\title{
Caregivers' perspectives on decision making about lung transplantation in cystic fibrosis
}

\author{
Elisabeth P. Dellon, MD, MPH, Mitchell D. Shores, BA, Katherine I. Nelson, MPH, Joanne \\ Wolfe, MD, MPH, Terry L. Noah, MD, and Laura C. Hanson, MD, MPH \\ University of North Carolina, Chapel Hill, North Carolina (EPD, MDS, KIN, TLN, LCH), Children's \\ Hospital Boston and Dana Farber Cancer Institute, Boston, Massachusetts (JW)
}

\begin{abstract}
Context-Lung transplantation extends survival for some patients with advanced cystic fibrosis, but it is complicated, has many potential risks, and its outcomes are difficult to predict. No standards exist for informed decision making about transplantation.
\end{abstract}

Objective-To assess decision making from the perspective of caregivers of patients who faced the transplant decision before dying of cystic fibrosis or transplant complications.

Design-Semistructured interviews with descriptive and qualitative content analysis.

Participants-Twenty-eight caregivers of patients with cystic fibrosis who received care at our center and died between 1996 and 2006.

Results-Of 28 patients who considered lung transplantation, $19(68 \%)$ received transplants, 6 $(21 \%)$ died while waiting for transplant, and $3(11 \%)$ declined transplant. Three caregivers $(11 \%)$ thought that the patient did not fully understand the reason for transplant referral. Five (18\%) thought that the patient did not fully understand potential risks. Ten (36\%) thought that alternatives were not fully understood. The only alternatives to transplant identified, progressive illness and the possibility of earlier death without transplant, were unacceptable to most. Thirteen caregivers (46\%) reported that the patient thought that declining transplant was not an option. Caregivers described the decision as "easy" for 19 (68\%), often expressing a sentiment of "do or die." Those who described the decision as "easy" recalled fewer elements of informed decision making.

Conclusions-From caregivers' reports, patients with cystic fibrosis may not fully understand risks of and alternatives to lung transplantation. Because a strong desire to prolong life necessitates honest communication about potential outcomes, interventions are needed to facilitate high-quality decision making.

Cystic fibrosis is the most common lethal genetic disease among whites. The natural history of cystic fibrosis is a progressive decline in lung function due to chronic infection, with death usually resulting from respiratory failure. ${ }^{1}$ Advances in treatments for cystic fibrosis have lengthened survival over time, and predicted median survival in the United States is currently 37.4 years. ${ }^{2}$ Lung transplantation is a therapeutic option that may improve survival

Corresponding author: Elisabeth P. Dellon, MD, Department of Pediatrics, Division of Pulmonology, CB \#7217, 5119-B

Bioinformatics Building, 130 Mason Farm Road, UNC School of Medicine, Chapel Hill, NC 27599-7217

(elisabeth_dellon@med.unc.edu), To purchase electronic or print reprints, contact: The InnoVision Group, 101 Columbia, Aliso Viejo,

CA 92656, Phone (800) 809-2273 (ext 532) or (949) 448-7370 (ext 532), Fax (949) 362-2049, reprints@ aacn.org.

Financial Disclosure

This work was supported by grants from the Cystic Fibrosis Foundation (DELLON07D0 and DELLON08A0) and the Agency for

Healthcare Research and Quality (U18HS10397-06, PI Alan Stiles). 
and quality of life for selected patients. ${ }^{3,4}$ It is the most intensive treatment available for advanced cystic fibrosis and is considered when a patient's survival is expected to be longer or quality of life greater with a transplant than without. ${ }^{5}$ However, long-term survival after lung transplant remains relatively poor overall, with only $50 \%$ to $60 \% 5$-year survival in recent analyses, ${ }^{6-8}$ and complications of lung transplants are the second leading cause of death in patients with cystic fibrosis. ${ }^{9}$

Although a consensus has been reached about disease-related factors affecting timing of referral for transplantation, ${ }^{10-12}$ no standards have been set for communicating and decision making with patients who have cystic fibrosis and their caregivers. The transplant decision is complex and deserves discussion among physicians, patients, and caregivers, with careful attention to outcomes and alternative treatments. Relevant outcomes include survival, potential complications, and quality of life. ${ }^{13}$ The primary alternatives to transplant include continued aggressive medical care and palliative treatment without transplant or transition to hospice care.

Informed decision making is the clinical and ethical practice standard for major treatment decisions that have significant risks and variable benefits. ${ }^{14}$ Cystic fibrosis is a lifethreatening disease, and transplantation is one of several reasonable treatment options. Because substantial uncertainty exists with regard to transplant outcomes, patients and caregivers must not only be informed, but their preferences should drive the decision. ${ }^{15}$ Informing patients and caregivers about lung transplantation according to this framework involves indepth discussions. Active participation of both patients and caregivers in the transplant decision, or shared decision making with physicians and other members of the health care team, is the current model of medical decision making. ${ }^{15,16}$

Patients and caregivers must understand that lung transplantation is being considered because their lung disease has progressed to the point where their predicted survival may be greater with transplant than without, ${ }^{5}$ and they must understand that their place on the waiting list will be determined by comparison of their medical issues and physiological parameters with those of others with severe lung disease who await transplantation; the goal is to get transplants for those in greatest need and those who would most likely derive the greatest benefit first. ${ }^{3}$ They must also understand the alternatives to transplant, up-to-date survival data, quality-of-life issues, and potential risks, including intraoperative morbidities and mortality and postoperative complications, including graft rejection, infection, and toxic effects of antirejection medications. ${ }^{17,18}$

Additionally, organ availability remains an issue, and some listed patients do not survive to transplant, with 79.3 deaths per 1000 patient-years occurring on the waiting list in $2006 .{ }^{9}$ Beyond addressing the factual information, uncertainties associated with the decision should be discussed, patients' and caregivers' understanding should be assessed, and patients' and caregivers' preferences for transplant compared with medical and palliative treatments without transplant should be explored. It is also appropriate to acknowledge that all of these factors may change over time.

The purpose of this study was to describe the current decision-making process for lung transplantation from the perspective of caregivers of patients who faced the transplant decision before dying of complications of cystic fibrosis or lung transplantation. We also examined the quality of informed decision making by comparing the experiences of patients who recalled more elements of informed decision making in discussions with physicians about transplant with the experiences of patients who recalled less. We hypothesized that most discussions would not fully address all elements of informed decision making and that 
higher quality decision making would follow from conversations about transplantation that incorporated more informed decision making.

\section{Methods}

Participants

We identified caregivers of all patients with cystic fibrosis who died of complications of cystic fibrosis or lung transplantation between 1996 and 2006 and received their primary care related to cystic fibrosis and/or transplant at our institution. Fifty-two caregivers listed as the primary contact for the patients in our hospital database were mailed letters requesting participation in a study about decision making and end-of-life events and were asked to return postage-paid letters if they wished not to be contacted by telephone. Sixteen could not be reached by telephone, 5 declined participation, and 3 were not directly involved in discussions about lung transplantation. When more than one caregiver of a given patient was available to participate, eligible caregivers self-selected for the interview. A total of 28 caregivers representing 28 caregiver-patient pairs answered interview questions about the transplant decision.

\section{Interviews}

Participants completed a semistructured interview about the experiences of corresponding patients who died of complications of cystic fibrosis or lung transplantation. Questions were derived from existing bereavement questionnaires, ${ }^{19-21}$ and we developed questions specific to the transplant decision by using a conceptual framework for informed decision making that outlines specific elements of informed decision making that should be included in discussions about complex medical decisions: discussion of the patient's role in decision making, the clinical issue or nature of the decision, the alternatives, the potential benefits and risks of the alternatives, uncertainties associated with the decision, assessment of the patient's understanding, and exploration of the patient's preferences. ${ }^{14}$ These elements were operationalized in 6 interview items with 4-point Likert scale responses. After answering each scaled item, respondents were asked to explain their answers, and their explanations were recorded verbatim. In addition, given the sensitive nature of the topic and the potential influence of the grieving process on responses, we asked a random subset of caregivers whether they considered the interview to be an emotional burden and whether they would recommend participation to other bereaved caregivers.

The interview script was reviewed by all investigators, approved by our institutional review board, and then pilot tested with 3 caregivers ( 2 parents, 1 sibling) of patients who died of cystic fibrosis. One investigator (E.D.) conducted all interviews by telephone after obtaining verbal informed consent from participants. Audio-taped interviews were professionally transcribed. Interviews were designed to last 60 minutes; mean length was 54 minutes (range, 30-90 minutes). Factual medical information reported by caregivers was verified by review of patient information contained in our cystic fibrosis database and by review of medical records.

\section{Data Analysis}

Summary statistics were used to analyze results to scaled and multiple-choice questions. Interview transcripts were reviewed and qualitative content analysis was used to delineate predominant themes from responses to open-ended questions. These themes served as codes that were then assigned to remaining transcripts independently by 2 investigators (M.S., K.N.) by using MAXQDA2007 (VERBI Software, Marburg, Germany). Codes were refined and further codes were developed as the analysis progressed. Differences in coding were reconciled by consensus. We tallied and averaged scaled responses to the 6 questions about 
inclusion of elements of informed decision and assigned subjects to 1 of 2 groups: those recalling "more" versus those recalling "less" informed decision making, with the median response score used as the cutoff point for "more" versus "less" informed decision making. Scores from those responding "don't know" were imputed to the median scaled score within the appropriate category.

\section{Results}

\section{Characteristics of Caregivers and Their Corresponding Patients}

The overall response rate of eligible caregivers was $60 \%$, and $86 \%$ of those who could be reached by telephone agreed to participate. Caregiver characteristics are summarized in Table 1. Most were mothers and identified themselves as primary caregivers.

Nonparticipants did not differ significantly from participants with regard to the age of the patient at death (24.4 years for nonparticipants vs 24.3 years for participants, $P=.90$ ), relationship to the patient ( $84 \%$ of non-participants were parents vs $82 \%$ of participants who were not parents; $P=.67$ ), patient's transplant status (58\% of nonparticipants vs $68 \%$ of participants underwent transplant, 2 in each group declined; $P=.56$ ), or length of survival after transplant (median 2.4 years for nonparticipants vs 3.5 years for participants; $P=.40$ ). Caregivers who declined participation did so for the following reasons: sadness about the death of their corresponding patients $(n=2)$, anger about the patient's death $(n=1)$, the desire to "keep only happy memories alive" $(\mathrm{n}=1)$, and acute medical issues with another child with cystic fibrosis $(\mathrm{n}=1)$.

Characteristics of corresponding patients are also summarized in Table 1. All patients died of respiratory failure due to advanced cystic fibrosis $(n=9)$ or complications of lung transplantation $(n=19)$, including early postoperative complications $(n=3)$, respiratory failure due to chronic rejection $(n=13)$, sepsis $(n=2)$, or other organ dysfunction related to use of immuno-suppressants $(\mathrm{n}=1)$. Cause of death was recorded from our institutional cystic fibrosis database and verified by review of medical records. Patients had died a mean of 6.7 years (range, 1.8-10.9 years) before the interview.

\section{Discussions With Physicians About Lung Transplantation}

We asked participants to recall discussions with physicians about lung transplantation. Responses to scaled questions are shown in Table 2, and recurrent themes and illustrative quotes from expanded answers to scaled questions are summarized in Table 3.

When asked about the patient's role in decision making and understanding of the decision, 25 care-givers $(89 \%)$ reported that the patient definitely played a role in the transplant decision. Three (11\%) reported that the patient did not fully understand the reason for referral for transplant. Two of these patients were children ( 1 young child and 1 adolescent); the other was an adult. In response to open-ended questions about the patient's role in the transplant decision, caregivers described the patient as the ultimate decision maker and reported supporting the patient's decision even when they disagreed. Regarding the patient's understanding of the decision, caregivers expressed that patients felt that their quality of life was poor and that transplant was the only remaining option. Patients had a strong desire to live longer; patients were not ready to stop fighting, nor were their caregivers.

With regard to alternatives to lung transplantation, only 16 caregivers (57\%) reported that the patient understood the alternatives very well; $36 \%$ questioned the patient's level of understanding. Caregivers voiced their understanding of alternatives to transplant, and responses included "usual care" for increasingly frequent and difficult to treat respiratory exacerbations and the possibility of earlier death without transplant. These alternatives were unacceptable to most patients and caregivers. Alternatives of continued medical and 
palliative care, hospice, or treatments designed to meet any goals other than survival, such as maximizing time outside the hospital, were not mentioned by any caregivers.

Caregivers reported that most patients understood potential benefits and risks of transplantation "very well," while nearly $20 \%$ understood less well or not at all. Most knew that risks were involved and recalled being given information about survival statistics. Several caregivers mentioned beliefs about leading a "normal life" after transplant and about transplant being a means of "buying time." Potential complications during surgery and the postoperative course and also complications of medications were poorly understood by many. Hearing about the experiences of prior transplant recipients before making the decision seemed to be helpful as this provided insight about trade-offs: many mentioned understanding that having a transplant means trading one set of problems or concerns for another.

Regarding uncertainties with the transplant decision, the decision to pursue transplantation was described as "very easy" or "somewhat easy" for 16 of the $25(64 \%)$ who did pursue it. A sentiment of "do or die" was expressed by most patients who chose to have a transplant. Some said that strong faith and/or reliance on the physician's recommendation made the decision easy. The remaining $9(32 \%)$ described the decision as "somewhat difficult" or "very difficult," citing worries about the surgery itself and also loss of control related to medical care after the transplant. The decision not to pursue transplant was described as "very easy" for all 3 who declined. Caregivers reported that these patients were "tired" and did not want to face a difficult posttransplant course. They also described concerns about outcomes of transplantation; interactions with previous transplant recipients seemed to influence their feelings. Ease or difficulty of the trans-plant decision did not correlate with reported understanding of risks or alternatives.

Finally, we asked about exploration of patients' preferences for or against transplantation. Only 10 caregivers (36\%) said that the patient felt that declining transplant was "definitely" an option; of these 10, 3 actually did decline transplant. Those who responded "definitely" knew that it was within their rights to decline, but did not see it as a practical option if their goal was survival. Belief about the option to decline transplantation did not correlate with reported understanding of risks or alternatives. Some caregivers who discussed their own preferences at the time of the transplant decision mentioned a feeling of "selfishness," noting that they encouraged their corresponding patients to pursue transplantation regardless of potential risks because of the possibility of prolonging their lives; they were not ready for them to die.

\section{Extent and Quality of Informed Decision Making About Lung Transplantation}

We assessed the quality of informed decision making by examining the frequency and extent of inclusion of elements of informed decision making in conversations between patients, caregivers, and physicians about lung transplantation. We divided participants into 2 groups: those recalling more informed decision making $(n=12)$ and those recalling less informed decision making $(\mathrm{n}=16)$. Caregivers of all 3 patients who declined transplant recalled more informed decision making. Themes and illustrative quotes from these 2 groups are summarized in Table 4. The difference in median patient survival after transplant between these groups was not statistically significant (2.4 years for those recalling more informed decision making versus 3.8 years for those recalling less; $P=.51$ ).

Both groups described direct involvement of the patient in the decision. Those recalling more informed decision making expressed that patients understood that their disease had progressed to the point where transplant might confer survival benefit and weighed pros and cons of transplantation, but did not find decision making as easy as those who recalled less 
informed decision making. In addition to finding the decision easier, those recalling less informed decision making seemed more confident about the transplant decision, expressing the importance of making a decision and standing by it. They also had beliefs and expectations that transplantation would provide the opportunity to lead a normal life. Neither group identified alternatives to transplant other than progression of disease and the possibility of earlier death without transplant.

\section{Discussion}

We sought to describe decision making about lung transplantation from the perspective of caregivers of patients with cystic fibrosis who faced this decision before dying of complications of cystic fibrosis or lung transplantation. We found that although most patients with cystic fibrosis play a major role in making the decision about lung transplantation, some have limited understanding of the risks of and alternatives to transplantation. Most do not feel that declining transplant is an option, which clearly reflects the desire to prolong survival. Additionally, the extent to which patients and caregivers are informed does not necessarily influence the decision for or against transplantation, and it is not clear that higher quality decision making follows from more extensive informed decision making. We also found that those who, by our criteria, are less informed, may actually find the decision to be easier than those who are more informed.

Whether our findings reflect an a priori decision about lung transplantation on the part of patients and caregivers or a need for improvement in discussions about transplantation is difficult to discern. Although the discrete elements of informed decision making must, according to ethical standards, be included in discussions about lung transplantation, our findings suggest that other factors can influence the quality of decision making and the decision itself. As survival in patients with cystic fibrosis continues to improve, ${ }^{9}$ so does hope for a longer lifespan, such that transplantation may not be as much a decision as a logical next step for some patients. The impact of the desire to prolong life and also of trust in medical providers, of advice from prior transplant recipients, and of religious faith and/or spirituality is most likely substantial for many patients. However, the logic of this step for many patients should not preclude adequate informed decision making for patients who may value goals other than maximizing survival. Thus, it is imperative that medical providers focus not just on factual information when discussing lung transplantation with patients and their caregivers, but also take time to elicit preferences and to understand goals.

Discussions about goals of care may allow patients and caregivers to consider alternatives to transplantation. It is striking that, in our study, no alternatives besides usual care and the possibility of earlier death were identified; recognizing and accepting alternatives is important given that not all patients survive to receive transplants and some are removed from the waiting list because of medical and psychosocial contraindications that arise after the initial decision is made. We must also acknowledge that the transplant decision may change over time. Repeated discussions about transplant and its alternatives would allow for shared decision making between patients, caregivers, and physicians and might improve the quality of decisions. ${ }^{15}$ These areas warrant further investigation, as we found no published reports addressing those issues in patients with cystic fibrosis or in other transplant populations.

This study had a number of limitations. First, we interviewed only caregivers whose corresponding patients died, and the views of caregivers of surviving patients may be different. We asked caregivers to recall details of discussions that took place many years before the interview. As cystic fibrosis is a relatively rare disease, the only way to collect adequate numbers of participants is to include patients over time. To assess accuracy of 
responses, we compared recalled events to factual demographic and diseasespecific information previously abstracted from medical records, and we found concordance. Using caregivers as surrogates for patients may misrepresent actual events or the feelings and opinions of patients themselves, but as caregivers are closely involved in the care of many patients with cystic fibrosis even into adulthood, ${ }^{22}$ including making complex medical decisions, their perspectives are useful in addressing the study questions.

Although the caregivers who participated in this study were recruited on the basis of the care of their corresponding patients at a single cystic fibrosis center, many of their corresponding patients had also discussed transplantation with physicians at other centers, thus their experiences may be more broadly representative. Additionally, in the context of the overall study, which also addressed end-of-life events, emotions may have influenced responses to questions about discussions of transplantation, particularly in the cases of extremely negative and extremely positive experiences and outcomes. We attempted to address this by surveying a random subset of caregivers about their perceptions of the interview, and none of the 12 surveyed described the interview as an emotional burden; all 12 said they would recommend participation in the study to other caregivers.

Despite these limitations, the findings of our study suggest areas for further exploration of the important issue of decision making about lung transplantation in patients with cystic fibrosis. Although we found that patients and caregivers who may be less informed about transplantation feel that the decision is easier and express more confidence in the decision, the transplant decision truly is complex and is made more difficult because selection of candidates is challenging and the current outcomes of lung transplantation in patients with cystic fibrosis are not optimal. Thus, it is essential that medical providers strive to fully inform patients and their caregivers about lung transplantation and its alternatives so that the decision is not simply when to transplant but rather whether to transplant or to identify and pursue acceptable alternatives to transplant.

More information is needed about how patients, their caregivers, and their health care providers make the decision and what other factors influence the quality of decision making. The development of standards for discussions with patients and their caregivers about lung transplantation and interventions to improve the decision making process should be considered in order to maximize quality of life for patients with advanced cystic fibrosis.

\section{Acknowledgments}

The authors are grateful to participating caregivers for their generosity with their time and their memories.

\section{References}

1. Davis PB, di Sant'Agnese PA. Assisted ventilation for patients with cystic fibrosis. JAMA. 1978; 239(18):1851-1854. [PubMed: 642113]

2. [Accessed May 8, 2009] Cystic Fibrosis Foundation Patient Registry: Annual Data Report. 2007. http://www.cff.org/research/ClinicalResearch/PatientRegistryReport

3. Egan TM, Murray S, Bustami RT, et al. Development of the new lung allocation system in the United States. Am J Trans-plant. 2006; 6(5 pt 2):1212-1227.

4. Gee L, Abbott J, Hart A, Conway SP, Etherington C, Webb AK. Associations between clinical variables and quality of life in adults with cystic fibrosis. J Cyst Fibros. 2005; 4(1):59-66. [PubMed: 15752683]

5. Yankaskas, JR.; Knowles, MR., editors. Clinical Pathophysiology and Manifestations of Lung Disease: Cystic Fibrosis in Adults. Lippincott-Raven; Philadelphia, PA: 1999.

6. Egan TM, Detterbeck FC, Mill MR, et al. Long term results of lung transplantation for cystic fibrosis. Eur J Cardiothorac Surg. 2002; 22(4):602-609. [PubMed: 12297180] 
7. International Society for Heart and Lung Transplantation. [Accessed May 8, 2009] 2008. http:// www.ishlt.org

8. Organ Procurement and Transplantation Network. [Accessed May 8, 2009] 2006. http:// optn.transplant.hrsa.gov

9. [Accessed September 25, 2009] Cystic Fibrosis Foundation Patient Registry: Annual Data Report. http://www.cff.org/UploadedFiles/research/ClinicalResearch/2006/20Registry/20Report.pdf

10. Egan TM, Kotloff RM. Pro/Con debate: lung allocation should be based on medical urgency and transplant survival and not on waiting time. Chest. 2005; 128(1):407-415. [PubMed: 16002964]

11. Noone PG, Egan TM. Cystic fibrosis: when to refer for lung transplantation-is the answer clear? Am J Respir Crit Care Med. 2002; 166(12 pt 1):1531-1532. [PubMed: 12471067]

12. Yankaskas JR, Mallory GB Jr. Lung transplantation in cystic fibrosis: consensus conference statement. Chest. 1998; 113(1):217-226. [PubMed: 9440593]

13. Kurland G, Orenstein DM. Lung transplantation and cystic fibrosis: the psychosocial toll. Pediatrics. 2001; 107(6):1419-1420. [PubMed: 11389266]

14. Braddock CH 3rd, Edwards KA, Hasenberg NM, Laidley TL, Levinson W. Informed decision making in outpatient practice: time to get back to basics. JAMA. 1999; 282(24):2313-2320. [PubMed: 10612318]

15. Whitney SN, Holmes-Rovner M, Brody H, et al. Beyond shared decision making: an expanded typology of medical decisions. Med Decis Making. 2008; 28(5):699-705. [PubMed: 18556639]

16. Charles C, Gafni A, Whelan T. Shared decision-making in the medical encounter: what does it mean? (or it takes at least two to tango). Soc Sci Med. 1997; 44(5):681-692. [PubMed: 9032835]

17. Trulock EP, Edwards LB, Taylor DO, Boucek MM, Keck BM, Hertz MI. The Registry of the International Society for Heart and Lung Transplantation: twenty-first official adult lung and heart-lung transplant report2004. J Heart Lung Transplant. 2004; 23(7):804-815. [PubMed: 15285066]

18. Studer SM, Levy RD, McNeil K, Orens JB. Lung transplant outcomes: a review of survival, graft function, physiology, health-related quality of life and cost-effectiveness. Eur Respir J. 2004; 24(4):674-685. [PubMed: 15459149]

19. University of Washington. [Accessed May 2009] Quality of Dying and Death Questionnaire for Family Members Version 3.2. http://depts.washington.edu/eolcare/instruments

20. Wolfe J, Grier HE, Klar N, et al. Symptoms and suffering at the end of life in children with cancer. N Engl J Med. 2000; 342(5):326-333. [PubMed: 10655532]

21. After-Death Bereaved Family Member Interview: Hospital Version. Brown University; 2000. http://www.chcr.brown.edu/pcoc/linkstoinstrumhtm.htm. [Accessed May 8, 2009]

22. Sawicki GS, Sellers DE, McGuffie K, Robinson W. Adults with cystic fibrosis report important and unmet needs for disease information. J Cyst Fibros. 2007; 6(6):411-416. [PubMed: 17452026] 


\section{Table 1}

Characteristics of caregivers participating in interviews and their corresponding patients $(\mathrm{N}=28$ patientcaregiver pairs)

\begin{tabular}{|c|c|}
\hline Characteristics of caregivers and patients & Value $^{a}$ \\
\hline \multicolumn{2}{|l|}{ Caregivers } \\
\hline \multicolumn{2}{|l|}{ Relationship to patient } \\
\hline Parent & $23(82)$ \\
\hline Grandparent & $1(4)$ \\
\hline Sibling & $1(4)$ \\
\hline Spouse & $2(7)$ \\
\hline Friend & $1(4)$ \\
\hline Age, median (range), y & $55(32-77)$ \\
\hline Female sex & $25(89)$ \\
\hline Primary caregiver to patient & $23(82)$ \\
\hline Other cystic fibrosis patient in family & $9(32)$ \\
\hline $\begin{array}{l}\text { Prior lung transplant for cystic fibrosis } \\
\text { in family }\end{array}$ & $2(7)$ \\
\hline Postsecondary education & $18(64)$ \\
\hline \multicolumn{2}{|l|}{ Patients } \\
\hline \multicolumn{2}{|l|}{ Lung transplant status } \\
\hline Underwent transplant & $19(68)$ \\
\hline Awaiting transplant & $6(21)$ \\
\hline Declined transplant & $3(11)$ \\
\hline Age at death, median (range), y & $24.3(8-42)$ \\
\hline Adults (age >18 years) & $21(75)$ \\
\hline Female sex & $15(54)$ \\
\hline \multicolumn{2}{|l|}{ Primary caregiver } \\
\hline Parent & $18(64)$ \\
\hline Grandparent & $1(4)$ \\
\hline Spouse & $4(14)$ \\
\hline Self & $5(18)$ \\
\hline $\begin{array}{l}\text { Survival after transplant, median } \\
\text { (range), y }\end{array}$ & $3.5(0.1-10.2)^{b}$ \\
\hline
\end{tabular}


Table 2

Responses to scaled questions about the transplant decision

\begin{tabular}{|c|c|}
\hline Element of informed decision making & No. $(\%)$ \\
\hline \multicolumn{2}{|c|}{$\begin{array}{l}\text { Discussion of patient's role in decision making: } \\
\text { patient played a role in decision making }\end{array}$} \\
\hline Definitely & $25(89)$ \\
\hline Probably & $0(0)$ \\
\hline Probably not & $1(4)$ \\
\hline Definitely not & $2(7)$ \\
\hline \multicolumn{2}{|l|}{$\begin{array}{l}\text { Alternatives: how well patient understood } \\
\text { alternatives to transplant }\end{array}$} \\
\hline Very well & $16(57)$ \\
\hline Somewhat well & $3(11)$ \\
\hline Not very well & $5(18)$ \\
\hline Not at all & $2(7)$ \\
\hline Don't know & $2(7)$ \\
\hline \multicolumn{2}{|c|}{$\begin{array}{l}\text { Potential benefits and risks: patient understood } \\
\text { potential benefits and risks of transplant }\end{array}$} \\
\hline Very well & $23(82)$ \\
\hline Somewhat well & $3(10)$ \\
\hline Not very well & $1(4)$ \\
\hline Not at all & $1(4)$ \\
\hline \multicolumn{2}{|c|}{$\begin{array}{l}\text { Uncertainties associated with the decision: ease of } \\
\text { transplant decision }\end{array}$} \\
\hline Very easy & $13(46)$ \\
\hline Somewhat easy & $6(21)$ \\
\hline Somewhat difficult & $5(18)$ \\
\hline Very difficult & $4(14)$ \\
\hline \multicolumn{2}{|c|}{$\begin{array}{l}\text { Assessment of the patient's understanding: patient } \\
\text { understood why referred for transplant }\end{array}$} \\
\hline Very well & $26(93)$ \\
\hline Somewhat well & $1(4)$ \\
\hline Not very well & $1(4)$ \\
\hline Not at all & $0(0)$ \\
\hline \multicolumn{2}{|c|}{$\begin{array}{l}\text { Exploration of patient's preferences: patient felt } \\
\text { that declining transplant was an option }\end{array}$} \\
\hline Definitely & $10(36)$ \\
\hline Probably & $5(18)$ \\
\hline Probably not & $2(7)$ \\
\hline Definitely not & $8(29)$ \\
\hline Don't know & $3(11)$ \\
\hline
\end{tabular}

Prog Transplant. Author manuscript; available in PMC 2013 August 29. 
Table 3

Recurrent themes and illustrative quotes from expanded responses to scaled questions about the transplant decision

\begin{tabular}{|c|c|c|}
\hline $\begin{array}{l}\text { Element of informed } \\
\text { decision making }\end{array}$ & Recurrent themes & Illustrative quotes \\
\hline $\begin{array}{l}\text { Discussion of patient's role in } \\
\text { decision making: patient played } \\
\text { a role in decision making }\end{array}$ & $\begin{array}{l}\text { Patient was the ultimate } \\
\text { decision maker } \\
\text { Caregivers supported patient's } \\
\text { decision even if they disagreed }\end{array}$ & $\begin{array}{l}\text { "She wanted to be on the list because she still had hope. But } \\
\text { I think she would have done it for the rest of us. Because } \\
\text { she thought that was what we wanted." } \\
\text { "It was absolutely her decision. And it was not the decision I } \\
\text { would have made for her." }\end{array}$ \\
\hline $\begin{array}{l}\text { Alternatives: how well patient } \\
\text { understood alternatives to } \\
\text { transplant }\end{array}$ & $\begin{array}{l}\text { Patient would die sooner } \\
\text { without a transplant } \\
\text { Treatments would become more } \\
\text { frequent and exacerbations } \\
\text { more difficult to treat over time }\end{array}$ & $\begin{array}{l}\text { "I know they could have done maybe the BiPAP or some } \\
\text { thing ... but that's not any way to live. I don't know, I think } \\
\text { she had just exhausted everything else there was to do." }\end{array}$ \\
\hline $\begin{array}{l}\text { Potential benefits and risks: } \\
\text { patient understood potential } \\
\text { benefits and risks of transplant }\end{array}$ & $\begin{array}{l}\text { Given information about } \\
\text { survival statistics } \\
\text { Knew there were risks involved } \\
\text { Having a transplant means } \\
\text { trading one set of problems } \\
\text { for another } \\
\text { Looked to transplant recipients } \\
\text { for information and advice }\end{array}$ & $\begin{array}{l}\text { "The physician was very honest in dealing with the percent } \\
\text { ages of people who ... you know, who didn't survive } \\
\text { the surgery. And ... then the longevity after the surgery. So I } \\
\text { think ... you know he [patient] weighed all those things } \\
\text { very carefully." } \\
\text { "Whatever it was it couldn't be any worse than what he was } \\
\text { experiencing then." }\end{array}$ \\
\hline $\begin{array}{l}\text { Uncertainties associated with } \\
\text { the decision: ease of } \\
\text { transplant decision }\end{array}$ & $\begin{array}{l}\text { Only option; "do or die" } \\
\text { Trusted recommendation of } \\
\text { physician } \\
\text { Strong faith dictated choice to } \\
\quad \text { pursue transplant }\end{array}$ & $\begin{array}{l}\text { "The way he was living it was not worth living. He needed to } \\
\text { take that chance." } \\
\text { "[The doctors] came in and told her that she would never } \\
\text { see her [next] birthday if she didn't have the lung trans } \\
\text { plant. Well we needed to make a decision right there, and } \\
\text { she decided to have it." } \\
\text { "He said that God wouldn't have told [the physician] to tell } \\
\text { him to have a lung transplant if he wasn't supposed to." }\end{array}$ \\
\hline $\begin{array}{l}\text { Assessment of the patient's } \\
\text { understanding: patient } \\
\text { understood why referred } \\
\text { for transplant }\end{array}$ & $\begin{array}{l}\text { Transplant was the only } \\
\text { remaining option } \\
\text { Quality of life was poor } \\
\text { Strong desire to live longer } \\
\text { Patient and caregivers were not } \\
\quad \text { ready to stop fighting }\end{array}$ & $\begin{array}{l}\text { "Oh, he understood completely." } \\
\text { "You know she was anticipating some time in the future and } \\
\text { when the time came she was ready." } \\
\text { "Yes, he understood it very well. He said it was, to him, it was, } \\
\text { you know, living the way he was living, it was not worth living." } \\
\text { "She knew she was going to die, so it was just a matter of, } \\
\text { hey, I need to do this." }\end{array}$ \\
\hline $\begin{array}{l}\text { Exploration of patient's } \\
\text { preferences: patient felt that } \\
\text { declining transplant was } \\
\text { an option }\end{array}$ & $\begin{array}{l}\text { Not an option if wanted to survive } \\
\text { Within rights of patient and } \\
\text { caregiver } \\
\text { Caregivers wanted patients to } \\
\text { have transplants; not ready to } \\
\text { lose them }\end{array}$ & $\begin{array}{l}\text { "I feel sure that he knew that death was a sure thing if he } \\
\text { didn't do it." } \\
\text { "It's like a lot of things when there are no other options ... } \\
\text { you know you're going for something that may extend your } \\
\text { life and most of us want to live." } \\
\text { "But you know, of course as a parent, if you can prolong } \\
\text { their life and keep them here with you, that is what you } \\
\text { want to do.you wanted them to have quality of life not } \\
\text { just quantity.but from a parent's standpoint, I really don't } \\
\text { think it [declining transplant] was an option." }\end{array}$ \\
\hline
\end{tabular}


Table 4

Themes and illustrative quotes related to extent of informed decision making in discussions with physicians about transplant

\begin{tabular}{|c|c|c|}
\hline $\begin{array}{l}\text { Element of informed } \\
\text { decision making }\end{array}$ & Recalled more informed decision making & Recalled less informed decision making \\
\hline $\begin{array}{l}\text { Discussion of patient's role } \\
\text { in decision making: } \\
\text { patient played a role in } \\
\text { decision making }\end{array}$ & $\begin{array}{l}\text { Definitely involved in the decision } \\
\text { "It was absolutely her decision. And it } \\
\text { was not the decision I would have made } \\
\text { for her." }\end{array}$ & $\begin{array}{l}\text { Definitely involved in the decision } \\
\text { "[Physician advised]...you know, that if she really } \\
\text { refused that we couldn't, that we shouldn't, force } \\
\text { her. But she didn't. She never, you know, refused." }\end{array}$ \\
\hline $\begin{array}{l}\text { Alternatives: how well } \\
\text { patient understood } \\
\text { alternatives to transplant }\end{array}$ & $\begin{array}{l}\text { Same treatments as always } \\
\text { Treatments would become more frequent } \\
\text { as disease progressed }\end{array}$ & $\begin{array}{l}\text { Same treatments as always } \\
\text { Going to get worse } \\
\text { Never talked about alternatives because never } \\
\text { considered not having a transplant }\end{array}$ \\
\hline $\begin{array}{l}\text { Potential benefits and risks: } \\
\text { patient understood poten } \\
\text { tial benefits and risks of } \\
\text { transplant }\end{array}$ & $\begin{array}{l}\text { Understood potential outcomes, survival } \\
\text { statistics } \\
\text { Physicians honest about possible outcomes } \\
\text { Many potential complications } \\
\text { Many pros and cons to weigh "It's just sometimes } \\
\text { you don't know what } \\
\text { something is going to be like. } \\
\text { It's one } \\
\text { thing to read about it. It's another thing } \\
\text { to actually do it." } \\
\text { "She said there was no sense in trading } \\
\text { one set of problems for another. She } \\
\text { said she would just play the cards she } \\
\text { was dealt." }\end{array}$ & $\begin{array}{l}\text { Transplant could be a "cure" for cystic fibrosis } \\
\text { Transplant would "buy time" } \\
\text { Could lead a normal life after transplant } \\
\text { Things might be difficult after surgery } \\
\text { "Whatever it was, it couldn't be any worse than what } \\
\text { he was experiencing then." } \\
\text { "And we weren't told that much....They did not talk } \\
\text { and explain that much to any of us." }\end{array}$ \\
\hline $\begin{array}{l}\text { Uncertainties associated } \\
\text { with the decision: ease of } \\
\text { transplant decision }\end{array}$ & $\begin{array}{l}\text { Only option; "do or die" } \\
\text { Weighed pros and cons } \\
\text { "So he had reservations, but when we got the call, we } \\
\text { went for it." } \\
\text { "I would say he was informed, it's just a very tough } \\
\text { decision." }\end{array}$ & $\begin{array}{l}\text { Only option; "do or die" } \\
\text { Important to make a decision and stick to it } \\
\text { "She had so much confidence in her doctor here, and } \\
\text { that's what he recommended." } \\
\text { "He [patient] and I saw a lung transplant as swapping } \\
\text { a more serious health problem for a slightly less } \\
\text { serious health problem... [patient's other parent] } \\
\text { saw it as a chance to get back to normal." }\end{array}$ \\
\hline $\begin{array}{l}\text { Assessment of the patient's } \\
\text { understanding: patient } \\
\text { understood why referred } \\
\text { for transplant }\end{array}$ & $\begin{array}{l}\text { Definitely understood reason for referral } \\
\text { "She knew that you won't be put on the } \\
\text { list unless your life expectancy is, you } \\
\text { know, } 3 \text { years or less and, you know, } \\
\text { she'd be changing the scope of what } \\
\text { she was dealing with." }\end{array}$ & $\begin{array}{l}\text { Patient understood well because of his/her attributes } \\
\text { ["very intelligent," "knew his/her body"] } \\
\text { "She knew she was going to die, so it was just } \\
\text { a matter of, hey, I need to do this." }\end{array}$ \\
\hline $\begin{array}{l}\text { Exploration of patient's } \\
\text { preferences: patient felt } \\
\text { that declining transplant } \\
\text { was an option }\end{array}$ & $\begin{array}{l}\text { Declining transplant was not an option if } \\
\text { the goal was to live longer } \\
\text { Knew there was a choice } \\
\text { "One of the things we discussed is just } \\
\text { because you are on the list doesn't } \\
\text { mean you have to accept the transplant. } \\
\text { You can change your mind." }\end{array}$ & $\begin{array}{l}\text { Declining transplant was not an option if the goal was } \\
\text { to live longer } \\
\text { Patient was in control } \\
\text { "I mean, we knew it was our right [to decline]." }\end{array}$ \\
\hline
\end{tabular}

